\title{
LETRAMENTO E MICROCULTURA: UM ESTUDO SOBRE GRAFOCENTRISMO E AMBIENTAÇÃO FAMILIAR
}

\author{
LITERACY AND MICROCULTURE: A STUDY ON GRAPHOCENTRISM AND \\ FAMILY AMBIENCE
}

Michelle Donizeth Euzébio

Universidade Federal de Santa Catarina - PPGLg

\begin{abstract}
Resumo
O presente estudo focaliza a caracterização dos usos sociais da escrita. Seu objetivo é descrever quais eventos e práticas de letramento ocupam lugar na rotina de mulheres da terceira idade, assim como depreender representações acerca dessa modalidade de língua evidenciadas nas falas dessas senhoras, tematizando a interface entre língua escrita e microcultura. As discussões sobre o tema ancoram-se em estudos de Street (1984; 2003; 2007); Barton (1994); Barton e Hamilton (1998); Barton, Hamilton e Ivanic (2000). Para tanto, a pesquisa buscou responder às seguintes questões: Como se caracterizam usos sociais da língua escrita na vida dessas mulheres? Que significados elas atribuem à língua escrita? Quais práticas e eventos de letramento são possíveis de descrever/depreender no cotidiano dessas senhoras? Os dados foram obtidos por meio de entrevistas, observação e notas de campo, focalizando os elementos visíveis nos eventos de letramento, tal qual suscitado nos estudos de Hamilton (2000a); já os constituintes não-visíveis das práticas de letramento foram observados durante a interação. As participantes são três mulheres habitantes do município de Garopaba/SC. Uma das senhoras, referida aqui como S1, mantém pouco contato com eventos de letramento de grupos escolarizados. As outras senhoras, doravante S2 e S3, por outro lado, constantemente estão em contato com eventos de letramento de grupos escolarizados. O estudo sugere, por meio dos resultados, a prevalência de concepções de modelo autônomo de letramento no ideário dessas mulheres tanto quanto aponta para diferenças expressivas entre as senhoras no que tange a práticas e eventos de letramento relacionados à escolarização dos familiares.
\end{abstract}

Palavras-chave: Práticas e eventos de letramento. Língua escrita. Microcultura.

\begin{abstract}
This study focuses on the characterization of the social uses of writing. The objective is to describe which practices and events of literacy have a place in the routine of elderly women, as well to observe the representations about this modality of language in their lives, thematising the interface between written language and microculture. The discussions on the topic are anchored in studies of Street $(1984 ; 2003$; 2007); Barton (1994); Barton e Hamilton (1998); Barton, Hamilton e Ivanic (2000). The study has searched to answer the following questions: How are characterized the social uses of written language in these women's lives? What meanings do they attach to the written language? Which practices and events of literacy can be described/observed from these ladies' routine? The data were obtained through interviews, observation and field notes, focusing on the visible elements in literacy events, as it was raised in the studies of
\end{abstract}


Hamilton (2000a); since the non-visible constituents of literacy practices were observed in the interaction. The participants are three women inhabitants of the city of Garopaba/SC. One of the ladies, referred here as S1, has little contact with literacy events of groups that attend school. Other ladies, here S2 and S3, moreover, are constantly in contact with literacy events of groups that attend school. The study suggests by the results the prevalence of conceptions of autonomous model of literacy in the ideals of these women as well points to expressive differences between the women on what concerns to practices and events of literacy, related to the level of education of the family.

Keywords: Practices e events of literacy. Written language. Microculture.

\section{INTRODUÇÃO}

Nos últimos anos, sobremodo a partir da década de 1980, tem-se observado uma nova perspectiva acerca dos estudos do letramento. No entendimento de Hamilton (2000b), a essência dessa abordagem consiste na compreensão do letramento não em termos de níveis de habilidades, mas definido em termos de práticas sociais e comunicativas com as quais os indivíduos se envolvem em vários domínios de sua vida. Desse modo, o letramento deve ser visto como histórica e socialmente situado. Sob essa perspectiva, os usos da língua escrita tendem a contribuir na configuração cultural dos diferentes grupos sociais. Baseado nessas suposições, podemos inferir que práticas de letramento singularizam diferentes comunidades, o que traz implicações, por exemplo, no modo como os indivíduos lidam com os eventos de letramento prevalecentes em sua microcultura ${ }^{1}$.

Com base em tais considerações, o tema deste artigo constrói-se sobre a interface entre língua escrita e microcultura. As participantes são três mulheres de um grupo de terceira idade, moradoras do município de Garopaba/SC. O objetivo deste estudo é depreender/descrever, com base em teorizações de Hamilton (2000a), quais eventos e práticas de letramento ocupam lugar na rotina dessas mulheres, assim como depreender representações acerca dessa modalidade da língua evidenciadas em suas falas.

As teorizações que ancoram a discussão são textos sobre o tema, a exemplo de Street (1984; 2003; 2007), Barton (1994); Barton e Hamilton (1998); Barton, Hamilton e Ivanic (2000). A estrutura do artigo configura-se em seções conceituais distintas: primeiramente, registramos a ancoragem teórica; em seguida, particularizamos o processo de geração de dados; posteriormente, procedemos à análise, seguida da seção de considerações finais.

\section{LETRAMENTO: RESSIGNIFICAÇÕES DOS USOS SOCIAIS DA ESCRITA}

A língua escrita, que apenas recentemente parece ter ganhado legitimidade como objeto de pesquisa no campo dos estudos linguísticos, ora é tomada em uma perspectiva voltada para as relações sociais mais amplas, ora é objeto de discussões que focalizam a imanência do sistema. Os estudos do letramento, no que concerne aos modelos

\footnotetext{
${ }^{1}$ Por microcultura, entendemos, aqui, o entorno família, igreja, vizinhança.
} 
autônomo e ideológico, potencializam esse movimento: a escrita tomada sob um olhar de imanência como processo cognitivo - concepção contra a qual se posiciona Street $(1984 ; 2003 ; 2007)$ - e a escrita tomada sob um olhar sociocultural efetivo, respectivamente - concepção em favor do qual se posicionam, hoje, teóricos do letramento (STREET, 1984; 2003; 2007; BARTON, 1994; BARTON; HAMILTON 1998; BARTON; HAMILTON; IVANIC, 2000; GEE, 2004).

Esse conceito, sob a perspectiva de imanência, pode ser concebido como necessariamente vinculado à alfabetização ou como forma de categorizar as pessoas como sendo mais ou menos eruditas (TINOCO, 2008). Sob esse ponto de vista, há uma associação entre letramento e escolaridade, sobretudo em pesquisas que se referem a níveis ou graus de letramento, uma vez que alguns pesquisadores classificam e equiparam esses termos a níveis ou graus de escolaridade. No entendimento da autora, ao classificar o fenômeno do letramento em níveis ou graus, há uma valorização das práticas de letramento escolar, assim como das práticas das instituições de prestígio, a exemplo das Igrejas, das universidades, dos organismos governamentais.

A partir da década de 1980, no entendimento de Kleiman (2008), o conceito de letramento foi ganhando ressignificação, sobretudo com os estudos do letramento, novos estudos do letramento e letramentos concebidos no plural, por meio de pesquisadores como Street (1984), Heath (1982), Barton (1994) e a própria Kleiman (1995). Sob esse ponto de vista, a língua escrita é tomada na perspectiva social, sendo, dessa forma, parte da configuração de entornos culturais de grupos sociais. Escreve Kleiman (2008, p.7):

\footnotetext{
Os estudos do letramento [...] refletem a inter e transdisciplinaridade características da pesquisa sobre a escrita e o ensino de língua materna nesse campo do saber e, também, a heterogeneidade de questões e problemas de pesquisa que aí se constituem: possíveis relações existentes entre os estilos cognitivos e as formas de socialização da linguagem; as relações de interdependência entre a fala e a escrita; os condicionantes que contribuem para o desenvolvimento de estilos diferentes de aprendizagem da leitura e da escritura; os processos sócio-históricos e culturais que influenciam os usos da língua escrita.
}

Definindo tal acepção como base, este estudo considera que indivíduos efetivamente inseridos em sociedades grafocêntricas são letrados. No entendimento de Kleiman (1995, p.19), “[...] podemos definir hoje letramento como um conjunto de práticas sociais que usam a escrita, enquanto sistema simbólico e enquanto tecnologia, em contextos específicos, para objetivos específicos."

Rojo (2009) ressalta que o fenômeno do letramento implica os usos e as práticas sociais às quais a escrita se presta, em contextos valorizados ou não-valorizados, nos mais variados espaços (família, escola, Igreja, mídias). De acordo com a estudiosa, as mais recentes abordagens acerca desses estudos têm apontado para a forma heterogênea, na qual as práticas sociais de leitura e escrita estão presentes, uma vez que as práticas de letramento são situadas socioculturalmente (BARTON, HAMILTON, IVANIC, 2000). Acerca disso, Kleiman (2008, p.18) argumenta que os "[...] estudos do letramento adotam um modelo situado das práticas de uso da língua escrita [...]", visto que, nessa 
perspectiva, qualquer aspecto descritivo ou explicativo acerca dos usos da língua escrita implica todos os eventos que compõem a situação comunicativa.

Sob esse novo ponto de vista, o conceito de letramento passa a ser designado no plural. Autores que adotam essa perspectiva, como Barton e Hamilton (1998); Hamilton (2000b), propõem, em seus estudos, os letramentos dominantes e os letramentos locais ou vernaculares. No entendimento de Barton e Hamilton (1998); Hamilton (2000b), os letramentos dominantes estão associados a organizações formais, tais como escola, Igreja, local de trabalho, comércio, nos quais estão previstos agentes como, por exemplo, professores, especialistas, padres, dentre outros. São padronizados em termos de efeitos formais da instituição, ao invés de serem definidos em termos de múltiplos propósitos e deslocamento dos cidadãos e de suas comunidades. Na medida em que esses letramentos são agrupados, são vistos como racionais e de elevado valor cultural. Já no que se refere aos letramentos vernaculares, a autora compreende que são essencialmente aqueles que não são regulamentados ou sistematizados por regras e procedimentos formais de instituições sociais, mas têm sua origem nos propósitos da vida cotidiana. Eles podem ser ativamente reprovados, banalizados e contrastados com os letramentos dominantes.

$\mathrm{Na}$ tentativa de ampliar as discussões sobre os usos sociais da escrita, Street (1984; 2003; 2007) propõe a existência de dois modelos: o modelo autônomo e o modelo ideológico aos quais já fizemos menção anteriormente. No modelo autônomo, a escrita seria tomada independentemente do contexto, apenas na perspectiva da imanência. Street $(2003$, p.4) escreve que, nessa concepção, "[...] a questão do letramento é com frequência representada como sendo simplesmente técnica: as pessoas precisam aprender uma forma de decodificar as letras, e depois poderão fazer o que desejarem com o recém-adquirido letramento." Sob essa perspectiva, as funções da linguagem são afetadas pelo domínio da escrita, sobretudo no que diz respeito a funções lógicas, visto que, nessa concepção, a escrita seria a única possibilidade de habilitar os indivíduos no desenvolvimento de abstrações. Desse modo, a escrita seria regida pela racionalidade e pela lógica inerente ao sistema, distinguindo-se da oralidade, que seria regida pelas relações interpessoais da linguagem, estabelecendo com ela uma dicotomia.

Street $(1984 ; 2003 ; 2007)$, que se mostra contrário a esse modelo, compreende que o letramento deve ser definido em termos de práticas sociais concretas, em que o contexto é determinante na maneira como os indivíduos lidam com a escrita. Desse modo, essa vertente pressupõe o letramento tomado como uma prática social e não apenas como produto técnico e neutro. Sob esse ponto de vista, o letramento está vinculado ao contexto social dos indivíduos. Essa discussão referente aos usos sociais da escrita remete a Barton (1994) e suas proposições acerca de eventos e práticas de letramento. Ancorado em estudos anteriores de Shirley Heath (1982) e Brian Street (1984; 1988), o autor entende que os eventos de letramento seriam as atividades humanas em que a escrita está presente, enquanto as práticas de letramento seriam as maneiras gerais como cada cultura utiliza o letramento, práticas nas quais as pessoas se baseiam quando participam de um evento de letramento.

Segundo o estudioso, a escrita desempenha diferentes funções na vida diária dos indivíduos, em múltiplas atividades nas quais essa modalidade da língua está presente; trata-se dos eventos de letramento. Esse fenômeno consiste em ações de que a leitura e a 
escrita fazem parte. Alguns eventos de letramento abrangem atividades diárias que abarcam a escrita, como a discussão de uma reportagem de jornal por um grupo de amigos, ou mesmo um ato de contar histórias para uma criança, fazendo remissão à obra escrita.

De acordo com Barton e Hamilton (1998), alguns eventos estão ligados a sequência de rotinas que podem consistir em etapas de procedimentos formais que correspondem a especificidades de instituições sociais, tais como o local de trabalho, escolas e organizações de assistência; outros eventos são estruturados com base em especificidades de relações humanas mais informais, estabelecidas no lar ou em grupos de convivência cotidiana.

As práticas de letramento, por sua vez, correspondem à maneira pela qual as culturas realizam a contação de histórias ancoradas em obras escritas, discussão de reportagens de jornais, produção de listas de compras etc. Grupos culturais distintos lidam de forma diferenciada com os usos e as práticas sociais de escrita. De acordo com Barton (1994), o estudo de diferentes práticas manifestadas pelos grupos sociais favorece a compreensão das diferentes formas de letramento. Um letramento é uma estável, coerente e identificável configuração de práticas tais como letramento legal ou o letramento específico de lugares de trabalho. Em situações multilíngues, no entendimento do autor, diferentes letramentos estarão frequentemente associados com diferentes línguas ou diferentes roteiros.

Barton e Hamilton (1998) caracterizam as práticas de letramento como culturalmente construídas. Desse modo, compreender o letramento contemporâneo consiste em documentar a forma na qual o letramento está situado historicamente, o que implica conceber as práticas de letramento como um fenômeno dinâmico e mutável, uma vez que tais práticas estão inseridas na vida e na sociedade, as quais - por sua vez e do mesmo modo -, são espaços, igualmente, passíveis de mudanças. Sob esse ponto de vista, no entendimento dos autores, importa compreeender implicações como ideologia, cultura e tradições nas quais tais práticas estão baseadas.

No entendimento de Hamilton (2000a), os eventos de letramento são apenas a ponta do iceberg de onde podem ser inferidas as práticas de letramento dos sujeitos envolvidos. Para a autora, os eventos são atividades locais, considerando que as práticas são padrões mais globais. Heath (1982 apud Street, 2003b, p.7) descreveu 'evento de letramento' como "[...] qualquer ocasião em que um texto escrito faça parte da natureza das interações dos participantes e de seus processos interpretativos".

É possível inferir, com base nessas considerações, que cada indivíduo, dependendo dos locais em que se encontra, fará usos diferentes da escrita. A escola e a casa constituem diferentes domínios, o que leva à consideração de que um mesmo evento pode assumir diferentes significados para os indivíduos. Parece certo, assim, que essas práticas de letramento são tomadas de forma distinta nas diferentes culturas, comunidades, espaços, repercutindo na maneira como os indivíduos lidam com os diferentes eventos de letramento. As considerações acerca dos usos sociais da escrita até aqui alinhavadas, nos motivaram a realizar o estudo descrito a seguir. 


\section{PARTICULARIZAÇÃO DOS PROCEDIMENTOS METODOLÓGICOS}

O estudo que constitui este artigo caracteriza-se como pesquisa qualitativa dada a intenção de gerar os dados de forma flexível e sensível ao contexto social, ao invés de produzir resultados estatísticos, tais como os estudos quantitativos. No entendimento de Neves (1996, p.1), a pesquisa qualitativa "[...] costuma ser direcionada, ao longo de seu desenvolvimento; além disso, não busca enumerar e medir eventos e, geralmente não emprega instrumental estatístico para análise dos dados; [...] seu foco de interesse é amplo e parte de uma perspectiva diferenciada da adotada pelos métodos quantitativos."

Nosso objetivo, neste estudo, foi depreender/descrever eventos e práticas de letramento que caracterizam a rotina de um grupo de mulheres da terceira idade moradoras do Município de Garopaba / SC. Baseado em tal consideração, este artigo atendeu às seguintes questões de pesquisa: Como se caracterizam os usos sociais da língua escrita na vida dessas mulheres? Que significados elas atribuem à língua escrita? Quais práticas e eventos de letramento são possíveis descrever/depreender no cotidiano dessas senhoras?

O processo de geração de dados implicou o uso de instrumentos da pesquisa qualitativa, tais como observação, análise documental e entrevistas. A interação foi feita de modo a depreender as concepções sobre a língua escrita dessas mulheres, assim como depreender o significado e a história das práticas e eventos de letramento predominantes em suas vidas.

O estudo teve por base as teorizações de Hamilton (2000a), acerca das práticas e eventos de letramento. Assim, o processo que envolveu entrevista, observação e análise documental teve como foco os elementos visíveis nos eventos de letramento, tais como participantes, ambientes, artefatos e atividades. Os constituintes não-visíveis das práticas de letramento, tais como participantes ocultos, domínio, recursos e rotinas serão objeto de atenção na vivência com os grupos/cidadãos ao longo do tempo de pesquisa, sendo descritos no tanto que o estreito período de tempo o permitiu.

De acordo com a autora, os participantes consistem em pessoas que interagem com materiais escritos. Desse modo, focalizamos como as mulheres informantes de pesquisa se apropriam da língua escrita e em que circunstâncias físicas imediatas o fazem, ou seja, em que ambiente essa interação acontece. Observamos os artefatos pelos quais são desenvolvidos o processo de interação, ou seja, que tipo de ferramenta ou acessório é utilizado nesse processo, além das atividades que consistem em ações realizadas pelos participantes no evento de letramento, como, por exemplo, ler jornais, fazer lista de compras, ler placas indicativas ou rótulos de alimento, dentre outros.

A realização desse estudo envolveu três senhoras moradoras do município de Garopaba/SC. A primeira informante, doravante S1, é viúva, tem setenta anos e cursou até a quarta série do Ensino Fundamental. Trabalhou durante muitos anos na lavoura juntamente com seu marido e atualmente está aposentada. Essa senhora mantém pouco contato com eventos de letramento típicos de grupos escolarizados. A segunda informante, aqui referida como S2, é dona de casa, tem 64 anos, cursou o Ensino Médio e atualmente está aposentada, sendo que durante alguns anos foi proprietária de um restaurante. Seu marido, também aposentado, tem curso superior e era proprietário de 
uma escola de informática. Essa senhora está em contato frequente com eventos de letramento de grupos escolarizados. Já a terceira informante, S3, é dona de casa, tem 65 anos e cursou até a quinta série do Ensino Fundamental. Seu marido também cursou até essa seriação escolar, trabalhou em um açougue e atualmente está aposentado. Cabe ressaltar, aqui, que S3 convive com sua filha e seu genro que são professores. Essa senhora, assim como S2, está em contato frequente com eventos de letramento de grupos escolarizados.

\section{UM OLHAR SOBRE PRÁTICAS E EVENTOS DE LETRAMENTO NO COTIDIANO DE MULHERES DA TERCEIRA IDADE}

Em nossa interação, primeiramente, perguntamos às senhoras se, no dia-a-dia, elas costumam ler jornais, livros, calendários, folhetos de promoções, listas telefônicas, bíblias, revistas, cartas, manuais de instruções e se escrevem cheques, listas de compras, receitas, entre outros eventos de letramento. As participantes responderam que todos esses eventos de letramento que apresentamos tomam parte de seu cotidiano. Quando interpeladas acerca de quais desses materiais usam com mais frequência, S1 enunciou: (1) Eu leio mais a Bíblia. É bom para a gente, na missa o padre ensina bastante coisa boa para a vida da gente. S2, por sua vez, disse: (2) Com certeza livros, mas também leio muitas noticias na tela do computador. Já S3 enunciou: (3) Ah, adoro livros. Esse ano, já li Capitu, de Machado de Assis e agora estou lendo o livro do Silvio Santos.

Importa destacar que alguns desses materiais escritos estão associados aos letramentos vernaculares, aos quais Hamilton (2000b) faz remissão, a exemplo de listas de compra e receitas, provavelmente muito presentes no cotidiano dessas senhoras. A autora assinala, porém, que muitos indivíduos tendem a hierarquizar alguns tipos de leitura e escrita em detrimento de outros, fenômeno esse observado nas respostas enunciadas por nossas participantes. Difícil crer que eventos de letramento como a leitura de obra de Machado de Assis sejam mais frequentes na vida dessas senhoras do que atividades cotidianas em que se valem da escrita. Ao que parece, tais senhoras ancoram suas respostas em discursos prototípicos provenientes de instituições de prestígio, organizações formais, ou seja, associados aos letramentos dominantes suscitados nos estudos de Barton e Hamilton (1998); Hamilton (2000b), tais como, nesse caso, a Igreja e a escola. Pudemos observar que esse discurso é similar em outras respostas enunciadas pelas entrevistadas, o que remete à provável prevalência, mesmo que nãoconsciente, de concepções de letramento vinculadas ao modelo autônomo (STREET, 1984; 2003; 2007), tão entranhadas no ideário popular.

Quando questionamos acerca da função da escrita na sociedade de hoje, S1 enunciou: (4) É para saber o que se vai fazer, para manter a gente informada, para se orientar. S2 relatou que a função da escrita é (5) Essencialmente para o aprendizado, adquirir conhecimento. Já S3 alega que é para (6) Instruir as pessoas, para ficar mais inteligente. Mais uma vez as respostas de S2 e S3 remetem às discussões de Street $(1984 ; 2003 ; 2007)$ acerca do modelo autônomo de letramento e secundarizam o papel da escrita na organização da vida diária, o que talvez tenha relações com sua convivência com membros da família de escolarização elevada. Já S1 conclui sua resposta com a frase (7) Se não for assim [usando a escrita] não podemos sair de casa, num evidente reconhecimento aos letramentos vernaculares. 
Esse discurso de valorização dos letramentos institucionais aparece também nas respostas enunciadas pelas senhoras referentemente à questão: o que mais gostavam e menos gostavam de ler: S1 enunciou: (8) Gosto da Bíblia para ajudar a família e gosto de jornal para saber o que tá acontecendo e não gosto daquelas coisas pornográficas. Eu leio o que serve para a minha família e que seja bom. S2, por sua vez, enunciou: (9) Gosto de livros de romance, suspense, místicos. Não gosto muito de ficção científica. Já S3 enunciou: (10) Gosto de história, daquela igual do Machado de Assis, da vida do Silvio Santos. De poesia eu não gosto. Não entendo o que ele quer dizer. Novamente S2 e S3 evidenciam focalização em eventos voltados à erudição, evidenciando o "discurso escolar que historicamente se reveste de um caráter prescritivo e regulador de comportamentos, [...]. Apesar de esse discurso não ter se constituído de maneira homogênea e coesa [...] ele é ideologicamente forte e trouxe [...] regulamentações e julgamento de valor." (GUEDES-PINTO, 2009, p.54)

Quando interpeladas sobre o que gostavam de escrever e do que não gostavam, S1 disse: (11) Gosto de escrever o que o padre fala na missa. Mas eu só escrevo quando eu estou assistindo à missa em casa; na Igreja eu só presto atenção. Não tem nada que eu não gosto de escrever. S2, por sua vez, relatou gostar de escrever poesias, crônicas, histórias e não disse nada que não gostasse de escrever. Já S3 enunciou: (12) Gosto de escrever lista de compras, mas eu adoro mais nomes de pessoas e lugares. Aqui, excepcionalmente, S3 menciona eventos de letramentos vernaculares.

Outra questão que merece um olhar cuidadoso em de tratando de nosso foco é a resposta dada à questão $A$ vida hoje em dia exige mais o uso da escrita do que anos atrás? Por quê? Dê exemplos. S1 respondeu: (13) Exige mais. Antes não precisava pagar luz, água, ir no banco. A gente tinha poço e comida do que a gente plantava. Mais uma vez, S1 parece menos permeada pelo discurso do modelo autônomo, possivelmente em razão de não manter convivência estreita com familiares de elevada escolarização, tal qual acontece com S2 e S3. S2 disse: (14) Sim, com certeza. A demanda de hoje exige muito o uso da língua escrita. Já S3 respondeu que "sim", mas não soube dizer por quê. Já quando perguntamos Hoje em dia a senhora lê e escreve mais do que quando era jovem, ou anos atrás usava a escrita de forma mais frequente? A que atribui isso?, S1 disse que em sua vida nada mudou, que o tipo de leitura e escrita que fazia antes é o mesmo de agora. S2 enunciou: (15) Hoje. Com certeza tenho conhecimento bem mais avançado. Já S3 disse que atualmente lê e escreve muito mais, visto que tem muito mais acesso a esses tipos de materiais. A diferença entre a resposta de $\mathrm{S} 1$ e as respostas de S2 e S3 mais uma vez remete às diferenças na ambientação familiar.

Cabe aqui referenciar Barton, Hamilton e Ivanic (2000) a respeito da forma heterogênea que caracteriza as práticas sociais de leitura e escrita. No entendimento dos autores, as práticas de letramento são situadas socioculturalmente. Podemos constatar, por meio das respostas enunciadas pelas informantes que os eventos e as práticas de letramento foram se ampliando substantivamente mais na vida de S2 e S3. Possivelmente isso se deva ao contato com mais diversos eventos de letramento, uma vez que essas informantes se relacionam constantemente com indivíduos inseridos em grupos escolarizados. Tendo presente os estudos de Barton (1994), podemos supor que as práticas de letramento do entorno familiar de S2 e S3 sejam diferentes do entorno familiar de S1. 
Ao serem interpeladas sobre o tipo de leitura mudou?Em quê?, S1 e S2 não souberam responder. S3, por sua vez, enuncia: (16) Sim, antes era mais infantil, hoje não. A despeito de pedirmos para falarem sobre as leituras que acham mais dificeis, S1 alegou não entender as revistas pornográficas, enunciando: (17) Isso não é para mim, as outras coisas eu entendo, mas isso não. S2, por sua vez, disse que nunca se deparou com algum tipo de leitura que achasse difícil. Já S3 alegou não entender poesias. Quando interpeladas sobre o que fazem quando não entendem algo que estejam lendo ou quando não conseguem escrever algo que precisa ser escrito, S1 alegou que pede ajuda à família, S2 enunciou: (18) Certamente, procuro esclarecimento. Já S3 disse: (19) Eu paro e fico raciocinando para entender.

Um momento marcante em nossa pesquisa diz respeito a um período da entrevista com a informante S1. Quando perguntamos em sua história de vida, há algum episódio, lembrança ou fato em que a escrita esteve presente e que foi marcante para a senhora?, S1 enunciou: (20) Foi a oração que eu copiei de um livro para o meu marido. Como ele não estava enxergando direito, copiei com uma letra bem grande. Nesse momento S1 começou a chorar. Vale lembrar que essa senhora ficou viúva há apenas seis meses. Esse fato envolvendo sentimento e espiritualidade remete aos constituintes não-visíveis das práticas de letramento mencionados nos estudos de Hamilton (2000a). No entendimento da autora, alguns recursos são trazidos para as práticas de letramento, tais como valores não-materiais, modos de pensar, sentimentos. Essas implicações também aparecem nas respostas enunciadas pelas outras informantes: S2 relatou: (21) O que me marcou muito foi duas cartinhas que meus filhos fizeram e me entregaram no dia das mães. S3, por sua vez, enunciou: (22) Me marcou a cartinha que meu netinho me deu quando aprendeu a ler e escrever.

Essas senhoras vivem em um mesmo bairro e costumam frequentar os mesmos locais da cidade, tais como Igreja, supermercado, lojas, bancos, entre outros. Desse modo, parece que a questão central para a participação de eventos e o delineamento de práticas de letramento consiste na ambientação familiar da qual provém essas senhoras. S1 e S3 não apresentam grandes disparidades no que se refere à escolarização, no entanto, S3 mantém maior contato com eventos de letramento típicos de grupos escolarizados o que lhe faculta maior acesso a bens culturais provenientes desse meio.

\section{CONSIDERAÇÕES FINAIS}

Este estudo, focado nas relações entre língua escrita e cultura buscou identificar quais eventos e práticas de letramento ocupam lugar na rotina de um grupo de mulheres da terceira idade, assim como depreender representações acerca dessa modalidade da língua evidenciadas nas falas dessas senhoras. Os resultados sugerem que o entorno familiar tende a ser determinante na maneira pela qual as informantes concebem os eventos de letramento, tanto quanto evidenciam a força de concepções de modelo autônomo entranhadas nas relações sociais. Podemos inferir, com base nas respostas enunciadas pelas participantes, que as vivências de $\mathrm{S} 1$ com a língua escrita parecem distintas das vivências de S2 e S3; ainda que compartilhem um mesmo espaço social, a ambientação familiar dessas senhoras parece contribuir na distinção de suas concepções sobre os usos da escrita. 


\section{REFERÊNCIAS}

BARTON, David. Literacy - an introduction to the ecology of written language. Cambridge/USA: Brackwell, 1994.

.; HAMILTON, Mary. Local Literacies: reading and writing in one community. London: Routledge, 1998.

.; IVANIC, R. Situated literacies. London: Routledge, 2000.

GEE, P.J. Situated language and learning: a critique of traditional schooling. Londres: Routledge, 2004

GUEDES-PINTO, Ana Lúcia. Fragmentos de histórias de leitura e escrita de professoras-alfabetizadoras na cidade de Campinas na contemporaneidade do século XX. In: OLIVEIRA, Maria do Socorro; KLEIMAN, Angela. Letramentos múltiplos. Natal/RN: UDUFRN, 2008, p. 41-61.

HAMILTON, Mary. Expanding the new literacy studies: using photographs to explore literacy as social practice. In: BARTON, David; HAMILTON, Mary; IVANIC, Roz (Org.) Situated literacies. London: Routledge, 2000a.

HAMILTON, Mary . Sustainable literacies and the ecology of lifelong learning, London, 2000b.

KLEIMAN, Angela. (Org.) Os significados do letramento: uma nova perspectiva sobre a prática social da escrita. Campinas: Mercado de Letras, 1995

NEVES, José Luis. Pesquisa qualitativa - características, usos e possibilidades. Caderno de Pesquisas em Administração, São Paulo, Vol.1, n.3, $2^{\circ}$ Semestre/1996.

OLIVEIRA, Maria do Socorro; KLEIMAN, Angela. Letramentos múltiplos. Natal/RN: UDUFRN, 2008.

ROJO, Roxane. Letramentos múltiplos, escola e inclusão social. São Paulo: Parábola Editorial, 2009

STREET, Brian. Literacy in theory and practice. Cambridge: CUP, 1984.

Abordagens alternativas ao letramento e desenvolvimento. Teleconferência Brasil sobre o letramento, outubro de 2003. 2007.

; LEFSTEIN, Adam. Literacy: an advanced resource book. London: Routledge,

TINOCO, Glicia Azevedo. Mundos de letramento de professores em formação no agreste norte-riograndense. In: OLIVEIRA, Maria do Socorro; KLEIMAN, Angela. Letramentos múltiplos. Natal/RN: UDUFRN, 2008, p.63-92. 